\title{
A sobrecarga de cuidadores de pacientes com esquizofrenia: uma revisão integrativa da literatura
}

The burden of caregivers to patients with schizophrenia: a bibliographic literature review

Sobrecarga de cuidadores de pacientes con esquizofrenia: una revisión integrativa de literatura

Nayara Fernanda Hansen ${ }^{1}$, Kelly Graziani Giacchero Vedana ${ }^{2}$, Adriana Inocente Miasso ${ }^{3}$, Edilaine Cristina da Silva Gherardi Donato ${ }^{4}$, Ana Carolina Guidorizzi Zanetti ${ }^{5}$

${ }^{1}$ Discente do curso de graduação em Enfermagem da Escola de Enfermagem de Ribeirão Preto da Universidade de São Paulo (EERP/USP). Ribeirão Preto, São Paulo, Brasil. E-mail: nayara.hansen@usp.br.

2 Enfermeira, Doutora em Enfermagem Psiquiátrica. Professora Doutora da EERP/USP. Ribeirão Preto, São Paulo, Brasil. E-mail: kellygiacchero@eerp.usp.br.

${ }^{3}$ Enfermeira, Doutora em Enfermagem. Professora Doutora da EERP/USP. Ribeirão Preto, São Paulo, Brasil. E-mail: amiassso@eerp.usp.br.

${ }^{4}$ Enfermeira, Doutora em Enfermagem Psiquiátrica. Professora Associada da EERP/USP. Ribeirão Preto, São Paulo, Brasil. E-mail: nane@eerp.usp.br.

${ }^{5}$ Enfermeira, Doutora em Enfermagem Psiquiátrica. Professora Doutora da EERP/USP. Ribeirão Preto, São Paulo, Brasil. E-mail: carolzan@eerp.usp.br.

\section{RESUMO}

Foi realizada uma revisão integrativa da literatura com o objetivo de identificar as evidências disponíveis na produção científica nacional e internacional sobre os motivos responsáveis pela ocorrência da sobrecarga em cuidadores de pacientes com esquizofrenia. A coleta de dados foi realizada nas bases de dados Pubmed, LILACS e CINAHL, por meio do cruzamento dos descritores sobrecarga/burden, família/family e esquizofrenia/schizophrenia. Foram encontradas 14 publicações que atenderam aos critérios de seleção. Os resultados mostraram que os motivos para a ocorrência da sobrecarga estão associados à sintomatologia da esquizofrenia, ausência de apoio social, preocupações com o futuro, alterações na vida social, cuidados diários, fase inicial da esquizofrenia, mudanças na rotina, preconceito, fatores sociodemográficos e fatores socioeconômicos, como as dificuldades financeiras. Esses achados contribuem para o embasamento da implantação de intervenções efetivas direcionadas aos cuidadores, com vistas à diminuição da sobrecarga ocasionada pela esquizofrenia e melhora do prognóstico do paciente.

Descritores: Cuidadores; Esquizofrenia; Enfermagem Psiquiátrica.

\section{ABSTRACT}

An integrative literature review was performed with the objective to identify the evidence available in national and international scientific publications on the responsible reasons for the occurrence of burden among caregivers to patients with schizophrenia. Data collection was performed on Pubmed, LILACS and CINAHL databases by crossing the descriptors sobrecarga/burden, família/family and esquizofrenia/schizophrenia. A total of 14 publications meeting the inclusion criteria were found. The results showed that the reasons for the occurrence of burden are associated with the symptoms of schizophrenia, lack of social support, concerns about the future, changes in social life, daily care, initial phase of schizophrenia, changes in the routine, prejudice, sociodemographic factors and socioeconomic factors, as well as financial difficulties. These findings contribute for establishing the foundations for implementing effective interventions aimed at caregivers, with a view to reducing the burden caused by schizophrenia and improving the patient's prognosis.

Descriptors: Caregivers; Schizophrenia; Psychiatric Nursing.

\section{RESUMEN}

Se realizó revisión integrativa de literatura objetivando identificar las evidencias disponibles en la producción científica nacional e internacional sobre los motivos de la ocurrencia de sobrecarga en cuidadores de pacientes con esquizofrenia. Datos recolectados de bases de datos Pubmed, LILACS y CINAHL, mediante cruzamiento de descriptores sobrecarga/burden, familia/family y esquizofrenia/schizophrenia. Se encontraron 14 publicaciones cumpliendo con los criterios de selección. Los resultados mostraron que los motivos de ocurrencia de sobrecarga están asociados a la sintomatología de la esquizofrenia, ausencia de apoyo social, preocupaciones a futuro, alteraciones en la vida social, cuidados diarios, fase inicial de la esquizofrenia, cambios en la rutina, preconcepto, factores sociodemográficos y factores socioeconómicos como las dificultades financieras. Esos hallazgos contribuyen como base de implantación de intervenciones efectivas orientadas a los cuidadores apuntando a la disminución de la sobrecarga provocada por la esquizofrenia y a la mejora del pronóstico del paciente.

Descriptores: Cuidadores; Esquizofrenia; Enfermería Psiquiátrica. 


\section{INTRODUÇÃO}

A esquizofrenia é um transtorno de evolução crônica, caracterizado pela desorganização dos processos mentais e marcado por forte estigma. Em geral, a idade de início do transtorno varia entre 15 e 20 anos para os homens e entre 20 e 25 anos para as mulheres. Os sintomas são classificados como positivos relacionados à presença de delírios, alucinações e a desorganização do pensamento e da conduta, e negativos referentes às alterações no afeto, perdas cognitivas, avolição e anedonia. Apesar da existência de características hereditárias genéticas que colaboram para o surgimento do transtorno, esse fator não é determinante. Assim, não existe uma causa específica, e o seu tratamento deve envolver o cuidado contínuo associado à psicoterapia, terapêutica medicamentosa e socioterapia(1).

As mudanças ocorridas na assistência em saúde mental, a partir do movimento da reforma psiquiátrica, adotaram a reabilitação psicossocial como fundamental para o processo de reinserção do paciente na sociedade. Esse modelo pressupõe o envolvimento contínuo dos profissionais da saúde, pacientes e familiares.

Desse modo, os pacientes passaram a viver na comunidade e realizar seu tratamento em serviços de saúde extra-hospitalares. A família dos pacientes, por sua vez, se tornou a principal provedora de cuidados e apoio, porém, sem preparação e conhecimentos fundamentais para desempenhar essa função(2-3).

Neste contexto surge o cuidador, que é o indivíduo responsável por cuidar da pessoa doente, auxiliando-Ihe na execução de atividades rotineiras, tais como, alimentação, cuidados com higiene, administração de medicamentos, ida a consultas, entre outras. Esses cuidadores podem ser formais, que recebem salário para oferecer assistência e que geralmente são profissionais da saúde, ou informais, que são representados, principalmente, pelos familiares. Estes, não recebem remuneração e geralmente são do sexo feminino ${ }^{(3)}$.

A gravidade da esquizofrenia, os fracassos sociais dos pacientes e as dificuldades de interação geram sentimentos de frustração e desespero nos familiares ${ }^{(4)}$. O principal cuidador passa a colocar suas necessidades e vontades em segundo plano, podendo gerar acúmulo de responsabilidades, estresse, isolamento e custos financeiros adicionais, tornando-se sobrecarregado(3-4). A sobrecarga pode ser definida como o impacto causado no ambiente familiar pela convivência com o paciente envolvendo principalmente aspectos emocionais e econômicos aos quais os cuidadores são envolvidos ${ }^{(4-5)}$.
Nessa vertente, o conceito de sobrecarga envolve dois aspectos, a sobrecarga objetiva e a subjetiva. A primeira refere-se às demandas concretas, como excesso de tarefas, supervisão de comportamentos, dificuldades financeiras e perturbações na rotina e vida social do cuidador. A sobrecarga subjetiva está relacionada ao universo dos sentimentos, preocupações com o presente e futuro do paciente, incômodo em lidar com situações problemáticas, sentimentos de perda, culpa, vergonha, impotência e desamparo ${ }^{(6)}$.

Estudos conduzidos com a finalidade de avaliar a sobrecarga de cuidadores de pacientes com esquizofrenia indicam a necessidade de maior compreensão dos principais motivos responsáveis por desencadear a sobrecarga, para que medidas efetivas e específicas de prevenção e tratamento da esquizofrenia possam ser estruturadas ${ }^{(3-7)}$.

Portanto, o presente estudo buscou encontrar na literatura um melhor entendimento dos motivos geradores da sobrecarga vivida pelos cuidadores de pacientes com esquizofrenia. Cabe ressaltar, que esses cuidadores são expostos constantemente aos efeitos, muitas vezes, negativos da esquizofrenia e também necessitam de assistência e suporte dos serviços de saúde e outros órgãos. Assim, a identificação dos motivos que desencadeiam a sobrecarga de cuidadores pode fornecer subsídios importantes para a estruturação de programas de intervenção efetivos em saúde mental, que envolvam a participação de pacientes com esquizofrenia e de seus cuidadores. O retorno e a permanência da pessoa com transtorno mental em seu núcleo familiar e social é a base da atual política de saúde mental brasileira.

Dessa forma, o presente estudo teve como objetivo identificar as evidências disponíveis na produção científica nacional e internacional sobre os motivos responsáveis pela ocorrência da sobrecarga em cuidadores de pacientes com esquizofrenia.

\section{MÉTODO}

Para o alcance do objetivo proposto, optou-se por realizar uma revisão integrativa da literatura. A revisão integrativa é um método que permite a incorporação de evidências disponíveis na produção científica. É realizada de forma organizada com o intuito de aprofundar conhecimentos em determinada temática. Para a execução desta revisão foram percorridas seis etapas descritas a seguir: identificação do tema e elaboração da questão de pesquisa, estabelecimento de critérios de inclusão exclusão e seleção da amostragem, categorização dos estudos, avaliação dos estudos 
incluídos na revisão, discussão dos resultados e síntese do conhecimento $^{(8)}$.

Para guiar a revisão, formulou-se a seguinte questão: Qual é o conhecimento científico produzido a respeito dos motivos responsáveis pela ocorrência da sobrecarga em cuidadores de pacientes com esquizofrenia?

Para a busca dos artigos foram utilizadas as bases de dados CINAHL (Cumulative Index to Nursing and Allied Health Literature), LILACS (Literatura Latino-americana e do Caribe em Ciências e Saúde) e PubMed (National Library of Medicine). As palavras-chaves utilizadas foram burden, family e schizophrenia em inglês e em português sobrecarga, família e esquizofrenia.

Os critérios de seleção foram: artigos que retratassem o motivo da ocorrência da sobrecarga em cuidadores de pacientes com esquizofrenia, cuidadores informais que convivessem diariamente com o paciente, pacientes não institucionalizados no momento da pesquisa, artigos indexados nas bases de dados CINAHL, LILACS e PubMed, artigos publicados na íntegra e no período de 2002 a 2012, artigos publicados em inglês e em português.

$\mathrm{Na}$ base de dados CINAHL, foram encontrados 132 artigos, na base de dados LILACS foram localizados 10 artigos e na PubMed, 389, totalizando 531 artigos. Para a inclusão dos artigos, foi realizada a leitura exaustiva do título, resumo e palavras-chaves dos estudos para que fosse garantido que os mesmos contemplassem a questão norteadora da revisão. Em caso de dúvida a respeito da seleção, optamos por incluir o estudo para decisão final após leitura de seu conteúdo na íntegra.

Assim, após leitura exaustiva do título, resumo e palavras-chave foram excluídos 125 artigos da CINAHL, 374 artigos da Pubmed e quatro da LILACS, pois não se enquadravam nos critérios de seleção estabelecidos para o estudo. Dos sete artigos pré-selecionados para leitura na íntegra na base de dados CINAHL, três foram excluídos por terem sido realizados com pacientes institucionalizados e cuidadores formais. Em relação à base de dados Pubmed, 15 artigos foram pré-selecionados e após leitura do artigo na íntegra, 10 foram excluídos, pois não apresentavam clareza no método adotado, pacientes participantes estavam institucionalizados, presença de cuidadores formais, e que não conviviam diariamente com o paciente. Na base de dados LILACS foram pré-selecionados seis artigos, sendo apenas um excluído devido à ausência de clareza na apresentação do método aplicado. Desse modo, 14 artigos foram selecionados e analisados, sendo quatro de pesquisa qualitativa e 10 de pesquisa quantitativa, publicados entre 2006 e 2012.
Para a organização e tabulação dos dados, foi utilizado um instrumento de coleta de dados contendo o título da pesquisa, ano, autores, periódico de publicação, delineamento do estudo, local onde foi desenvolvida a pesquisa, objetivos do artigo, sujeitos estudados, resultados encontrados e conclusão/considerações.

Portanto, após a leitura de cada artigo selecionado foi realizado o preenchimento do instrumento de coleta de dados. Posteriormente, foram extraídas as principais informações abordadas em cada artigo e que correlacionavam com o objetivo do estudo. Em seguida, foi realizada, exaustivamente, a leitura da síntese dos artigos, com o propósito de verificar a contribuição de cada estudo para a elucidação da questão norteadora, de forma a atingir o objetivo previsto.

\section{RESULTADOS}

Os estudos analisados foram desenvolvidos no período de 2006 a 2012, oito estavam em inglês e seis em português. Considerando a formação acadêmica dos autores, sete foram escritos por enfermeiros, dois por médicos, dois por psicólogos, dois por médicos e psicólogos e um por enfermeiros e médicos.

Cabe destacar, que alguns dos estudos analisados utilizaram instrumentos de medida e foram capazes de identificar os motivos para a ocorrência da sobrecarga objetiva e subjetiva.

Os resultados da síntese dos artigos selecionados para análise foram apresentados no Quadro 1. 
Quadro 1. Síntese dos artigos selecionados para a revisão integrativa.

\begin{tabular}{|c|c|c|c|c|c|}
\hline $\begin{array}{c}\text { Título do } \\
\text { Periódico/ } \\
\text { Autores }\end{array}$ & $\begin{array}{c}\text { País de } \\
\text { origem/ ano } \\
\text { de publicação }\end{array}$ & $\begin{array}{l}\text { Delineamento } \\
\text { do estudo }\end{array}$ & Objetivo & $\begin{array}{c}\text { Motivos para ocorrência } \\
\text { da sobrecarga }\end{array}$ & Conclusão \\
\hline $\begin{array}{l}\text { Turkish } \\
\text { Journal of } \\
\text { Psychiatry } \\
\text { Gülseren } \\
\text { et al }{ }^{(9)}\end{array}$ & Turquia/ 2010 & $\begin{array}{l}\text { Descritivo, } \\
\text { quantitativo, } \\
\text { não } \\
\text { experimental, } \\
\text { transversal }\end{array}$ & $\begin{array}{l}\text { Analisar os fatores } \\
\text { relacionados à } \\
\text { sobrecarga de } \\
\text { cuidados em } \\
\text { familiares de } \\
\text { pacientes com } \\
\text { esquizofrenia. }\end{array}$ & $\begin{array}{l}\text { Os motivos da ocorrência } \\
\text { de sobrecarga foram } \\
\text { atribuídos às dificuldades } \\
\text { financeiras, presença de } \\
\text { sintomas positivos e } \\
\text { negativos do transtorno e } \\
\text { ausência de apoio social. }\end{array}$ & $\begin{array}{c}\text { Implantar estratégias } \\
\text { para melhorar o } \\
\text { desempenho social dos } \\
\text { pacientes e o apoio à } \\
\text { família. }\end{array}$ \\
\hline $\begin{array}{l}\text { Nursing and } \\
\text { Health } \\
\text { Sciences } \\
\mathrm{Li} \\
\text { et } \mathrm{al}^{(10)}\end{array}$ & China/2007 & $\begin{array}{c}\text { Descritivo, } \\
\text { quantitativo, } \\
\text { correlacional, } \\
\text { não } \\
\text { experimental, } \\
\text { transversal }\end{array}$ & $\begin{array}{l}\text { Conhecer o nível } \\
\text { de sobrecarga de } \\
\text { familiares de } \\
\text { pacientes com } \\
\text { esquizofrenia e } \\
\text { correlacioná-las às } \\
\text { características } \\
\text { sociodemográficas } \\
\text { e pessoais. }\end{array}$ & $\begin{array}{c}\text { O cuidado diário ao } \\
\text { paciente foi considerado } \\
\text { como principal } \\
\text { responsável pela } \\
\text { sobrecarga física e } \\
\text { alterações na vida social } \\
\text { dos cuidadores. No âmbito } \\
\text { da sobrecarga subjetiva, } \\
\text { os principais motivos } \\
\text { estavam relacionados às } \\
\text { preocupações com o } \\
\text { futuro. }\end{array}$ & $\begin{array}{c}\text { Buscar estratégias para } \\
\text { ampliar o suporte aos } \\
\text { familiares. }\end{array}$ \\
\hline $\begin{array}{l}\text { Social } \\
\text { Psychiatry and } \\
\text { Psychiatric } \\
\text { Epidemioly } \\
\text { Gonçalves- } \\
\text { Pereira } \\
\text { et al }{ }^{(11)}\end{array}$ & $\begin{array}{l}\text { Portugal/ } \\
2012\end{array}$ & $\begin{array}{l}\text { Descritivo, } \\
\text { quantitativo, } \\
\text { não } \\
\text { experimental, } \\
\text { transversal }\end{array}$ & $\begin{array}{l}\text { Compreender o } \\
\text { impacto da } \\
\text { esquizofrenia em } \\
\text { famílias de } \\
\text { pacientes com } \\
\text { esquizofrenia. }\end{array}$ & $\begin{array}{l}\text { O impacto do surgimento } \\
\text { da esquizofrenia e a baixa } \\
\text { produtividade dos } \\
\text { pacientes foram } \\
\text { considerados os } \\
\text { desencadeantes da } \\
\text { sobrecarga financeira. } \\
\text { Além disso, preocupações } \\
\text { com o futuro também } \\
\text { foram responsáveis por } \\
\text { gerar altos níveis de } \\
\text { sobrecarga. }\end{array}$ & $\begin{array}{c}\text { Destaca-se a } \\
\text { importância de um } \\
\text { vínculo entre os } \\
\text { profissionais de saúde } \\
\text { mental e os cuidadores. }\end{array}$ \\
\hline $\begin{array}{l}\text { Scandinavian } \\
\text { Journal of } \\
\text { Caring } \\
\text { Sciences. } \\
\text { Papastavrou } \\
\text { et al(12) }\end{array}$ & $\begin{array}{l}\text { Turquia/ } \\
2010\end{array}$ & $\begin{array}{l}\text { Descritivo, } \\
\text { quantitativo, } \\
\text { não } \\
\text { experimental, } \\
\text { transversal }\end{array}$ & $\begin{array}{c}\text { Investigar o nível } \\
\text { de sobrecarga do } \\
\text { cuidado de } \\
\text { familiares com } \\
\text { esquizofrenia e } \\
\text { correlacionar as } \\
\text { características } \\
\text { pessoais do } \\
\text { paciente e do } \\
\text { cuidador. }\end{array}$ & $\begin{array}{c}\text { O principal fator } \\
\text { desencadeante da } \\
\text { sobrecarga foram os } \\
\text { comportamentos } \\
\text { agressivos dos pacientes e } \\
\text { as preocupações com } \\
\text { futuro. }\end{array}$ & $\begin{array}{c}\text { Ampliar apoio por parte } \\
\text { dos serviços de saúde } \\
\text { mental e outras } \\
\text { instituições aos } \\
\text { cuidadores. }\end{array}$ \\
\hline $\begin{array}{l}\text { Revista da } \\
\text { Escola de } \\
\text { Enfermagem } \\
\text { da USP. } \\
\text { Oliveira } \\
\text { et al }{ }^{(13)}\end{array}$ & Brasil/2011 & $\begin{array}{l}\text { Qualitativo } \\
\text { (história oral } \\
\text { temática) }\end{array}$ & $\begin{array}{c}\text { Identificar, entre } \\
\text { pais de pacientes } \\
\text { com esquizofrenia, } \\
\text { elementos de sua } \\
\text { convivência diária } \\
\text { com o transtorno } \\
\text { mental. }\end{array}$ & $\begin{array}{c}\text { As frustrações } \\
\text { relacionadas aos planos } \\
\text { pessoais e familiares } \\
\text { associadas ao fardo de } \\
\text { cuidar diariamente do } \\
\text { paciente aumentaram os } \\
\text { níveis de sobrecarga e } \\
\text { piora da qualidade de vida } \\
\text { dos cuidadores. }\end{array}$ & $\begin{array}{l}\text { Buscar estratégias } \\
\text { eficazes para melhorar } \\
\text { a qualidade de vida do } \\
\text { paciente e cuidador. }\end{array}$ \\
\hline $\begin{array}{l}\text { Psicologia em } \\
\text { estudo. } \\
\text { Souza Filho } \\
\text { et } \text { al }^{(14)}\end{array}$ & Brasil/2010 & $\begin{array}{l}\text { Descritivo, } \\
\text { quantitativo, } \\
\text { não } \\
\text { experimental, } \\
\text { transversal }\end{array}$ & $\begin{array}{c}\text { Avaliar a } \\
\text { sobrecarga } \\
\text { objetiva e } \\
\text { subjetiva em } \\
\text { cuidadores de } \\
\text { adultos portadores } \\
\text { de esquizofrenia. }\end{array}$ & $\begin{array}{l}\text { Os principais motivos para } \\
\text { a ocorrência da } \\
\text { sobrecarga estavam } \\
\text { associados as mudanças } \\
\text { na rotina, ter que } \\
\text { encorajar os pacientes a } \\
\text { tomarem medicações e se } \\
\text { ocuparem e preocupações } \\
\text { com futuro. }\end{array}$ & $\begin{array}{l}\text { Necessidade de um } \\
\text { trabalho com a família } \\
\text { para que superem as } \\
\text { dificuldades advindas } \\
\text { do transtorno. }\end{array}$ \\
\hline $\begin{array}{c}\text { Revista } \\
\text { Gaúcha de } \\
\text { Enfermagem. } \\
\text { Zanetti } \\
\text { et al }{ }^{(15)}\end{array}$ & Brasil/2007 & $\begin{array}{l}\text { Qualitativo, } \\
\text { estudo de caso } \\
\text { etnográfico }\end{array}$ & $\begin{array}{l}\text { Descrever o } \\
\text { impacto da } \\
\text { esquizofrenia na } \\
\text { família. }\end{array}$ & $\begin{array}{c}\text { A sobrecarga foi } \\
\text { relacionada à } \\
\text { sintomatologia da doença, } \\
\text { dificuldades financeiras, } \\
\text { dependência dos pacientes } \\
\text { e ao preconceito que os } \\
\text { familiares e pacientes } \\
\text { enfrentam perante a } \\
\text { sociedade. }\end{array}$ & $\begin{array}{c}\text { Ampliar a rede efetiva } \\
\text { de apoio na } \\
\text { comunidade e } \\
\text { implantar programas } \\
\text { de reabilitação } \\
\text { abrangentes podem } \\
\text { diminuir a sobrecarga. }\end{array}$ \\
\hline
\end{tabular}




\begin{tabular}{|c|c|c|c|c|c|}
\hline $\begin{array}{c}\text { Título do } \\
\text { Periódico/ } \\
\text { Autores } \\
\end{array}$ & $\begin{array}{c}\text { País de } \\
\text { origem/ ano } \\
\text { de publicação }\end{array}$ & $\begin{array}{l}\text { Delineamento } \\
\text { do estudo }\end{array}$ & Objetivo & $\begin{array}{c}\text { Motivos para ocorrência } \\
\text { da sobrecarga }\end{array}$ & Conclusão \\
\hline $\begin{array}{c}\text { Revista } \\
\text { Psiquiatria do } \\
\text { Rio Grande do } \\
\text { Sul. } \\
\text { Almeida et } \\
\text { al(16) }\end{array}$ & Brasil/2010 & $\begin{array}{l}\text { Qualitativo, } \\
\text { fenomenologia }\end{array}$ & $\begin{array}{l}\text { Avaliar os fatores } \\
\text { de sobrecarga em } \\
\text { cuidadores de } \\
\text { pacientes com } \\
\text { esquizofrenia. }\end{array}$ & $\begin{array}{l}\text { O início da esquizofrenia, } \\
\text { as dificuldades financeiras } \\
\text { e o isolamento social } \\
\text { foram os principais fatores } \\
\text { responsáveis pela } \\
\text { sobrecarga. }\end{array}$ & $\begin{array}{c}\text { É preciso promover } \\
\text { ações para diminuir os } \\
\text { agravos nas dimensões } \\
\text { física, psíquica e social } \\
\text { dos cuidadores. }\end{array}$ \\
\hline $\begin{array}{l}\text { Jornal } \\
\text { Brasileiro de } \\
\text { Psiquiatria. } \\
\text { Albuquerque } \\
\quad \text { et al }{ }^{(17)}\end{array}$ & Brasil/2010 & $\begin{array}{c}\text { Descritivo, } \\
\text { correlacional de } \\
\text { corte } \\
\text { transversal }\end{array}$ & $\begin{array}{c}\text { Investigar a } \\
\text { sobrecarga } \\
\text { objetiva e } \\
\text { subjetiva em três } \\
\text { diferentes tipos de } \\
\text { cuidadores. } \\
\end{array}$ & $\begin{array}{l}\text { No âmbito da sobrecarga } \\
\text { subjetiva os principais } \\
\text { motivos foram } \\
\text { relacionados às } \\
\text { preocupações com o } \\
\text { futuro. }\end{array}$ & $\begin{array}{l}\text { Implementar } \\
\text { estratégias de } \\
\text { assistência com a } \\
\text { inclusão dos } \\
\text { cuidadores. }\end{array}$ \\
\hline $\begin{array}{l}\text { Journal of } \\
\text { Clinical } \\
\text { Nursing. } \\
\text { Chien et al }{ }^{(18)}\end{array}$ & China/2007 & $\begin{array}{l}\text { Descritivo, } \\
\text { quantitativo, } \\
\text { não } \\
\text { experimental, } \\
\text { transversal }\end{array}$ & $\begin{array}{c}\text { Avaliar a } \\
\text { percepção de } \\
\text { sobrecarga de } \\
\text { familiares com } \\
\text { esquizofrenia e } \\
\text { testar as } \\
\text { associações com } \\
\text { características } \\
\text { sociodemográficas, } \\
\text { fatores familiares } \\
\text { e condições de } \\
\text { saúde. } \\
\end{array}$ & $\begin{array}{l}\text { Os principais motivos } \\
\text { foram: aumento da idade } \\
\text { dos cuidadores, baixas } \\
\text { condições } \\
\text { socioeconômicas e gênero } \\
\text { do paciente ou cuidador. }\end{array}$ & $\begin{array}{c}\text { Destaca-se a } \\
\text { importância da equipe } \\
\text { de saúde com a } \\
\text { finalidade de oferecer } \\
\text { assistência aos } \\
\text { cuidadores em todas as } \\
\text { suas dimensões. }\end{array}$ \\
\hline $\begin{array}{l}\text { Revista } \\
\text { Eletrônica de } \\
\text { Enfermagem. } \\
\text { Schülhi } \\
\text { et al }{ }^{(19)}\end{array}$ & Brasil/2011 & $\begin{array}{l}\text { Descritivo e } \\
\text { exploratório de } \\
\text { abordagem } \\
\text { qualitativa }\end{array}$ & $\begin{array}{c}\text { Conhecer o } \\
\text { cotidiano dos } \\
\text { familiares de } \\
\text { pacientes com } \\
\text { esquizofrenia } \\
\text { quanto aos } \\
\text { impactos do } \\
\text { cuidado. }\end{array}$ & $\begin{array}{c}\text { Os cuidadores } \\
\text { relacionaram a ausência } \\
\text { de apoio social como fator } \\
\text { desencadeante de } \\
\text { sobrecarga. }\end{array}$ & $\begin{array}{c}\text { Recomenda-se a } \\
\text { ampliação da atenção à } \\
\text { família para que a } \\
\text { sobrecarga seja } \\
\text { amenizada. }\end{array}$ \\
\hline $\begin{array}{l}\text { Journal of } \\
\text { Social } \\
\text { Psychiatry. } \\
\text { Igberase } \\
\text { et al }\end{array}$ & Nigéria/2010 & $\begin{array}{c}\text { Descritivo, } \\
\text { quantitativo, } \\
\text { não } \\
\text { experimental, } \\
\text { transversal }\end{array}$ & $\begin{array}{l}\text { Correlacionar as } \\
\text { características } \\
\text { sociodemográficas } \\
\text { com o nível de } \\
\text { sobrecarga } \\
\text { vivenciada por } \\
\text { cuidadores de } \\
\text { pacientes com } \\
\text { esquizofrenia. }\end{array}$ & $\begin{array}{c}\text { Houve correlação entre a } \\
\text { baixa escolaridade e altos } \\
\text { níveis de sobrecarga. } \\
\text { Cuidadores de pacientes } \\
\text { empregados mostraram } \\
\text { menores níveis de } \\
\text { sobrecarga. }\end{array}$ & $\begin{array}{c}\text { Destaca-se a } \\
\text { necessidade de } \\
\text { intervenções junto aos } \\
\text { pacientes e cuidadores. } \\
\text { Alternativas de } \\
\text { emprego para } \\
\text { pacientes também } \\
\text { devem ser } \\
\text { consideradas visando à } \\
\text { reabilitação psicossocial } \\
\text { e diminuição da } \\
\text { sobrecarga. }\end{array}$ \\
\hline $\begin{array}{c}\text { Mental Health } \\
\text { Nursing. } \\
\text { Ukpong }^{(21)}\end{array}$ & Nigeria/2006 & $\begin{array}{c}\text { Descritivo, } \\
\text { quantitativo, } \\
\text { não } \\
\text { experimental, } \\
\text { transversal }\end{array}$ & $\begin{array}{l}\text { Examinar fatores } \\
\text { sociodemográficos } \\
\text { e sintomas da } \\
\text { esquizofrenia e a } \\
\text { forma que estes } \\
\text { acarretam } \\
\text { sobrecarga para } \\
\text { os cuidadores. }\end{array}$ & $\begin{array}{l}\text { A presença dos sintomas } \\
\text { positivos e negativos da } \\
\text { esquizofrenia e as } \\
\text { dificuldades financeiras } \\
\text { foram fortemente } \\
\text { relacionadas ao aumento } \\
\text { da sobrecarga. Cuidadores } \\
\text { com baixa escolaridade e } \\
\text { condições } \\
\text { socioeconômicas precárias } \\
\text { mostraram maiores níveis } \\
\text { de sobrecarga. }\end{array}$ & $\begin{array}{c}\text { Variáveis } \\
\text { sociodemográficas e } \\
\text { características pessoais } \\
\text { dos pacientes e } \\
\text { cuidadores podem } \\
\text { interferir na } \\
\text { sobrecarga. Assim, este } \\
\text { estudo visou o } \\
\text { aprimoramento dos } \\
\text { saberes em saúde } \\
\text { mental para o cuidado } \\
\text { à família e ao portador } \\
\text { de esquizofrenia. }\end{array}$ \\
\hline $\begin{array}{l}\text { Journal of } \\
\text { Clinical } \\
\text { Nursing. } \\
\text { Tan } \\
\text { et al(22) }\end{array}$ & Cingapura/2012 & $\begin{array}{c}\text { Descritivo, } \\
\text { quantitativo, } \\
\text { não } \\
\text { experimental, } \\
\text { transversal }\end{array}$ & $\begin{array}{l}\text { Examinar os níveis } \\
\text { de sobrecarga e } \\
\text { estratégias de } \\
\text { enfrentamento } \\
\text { vivenciadas por } \\
\text { cuidadores de } \\
\text { pessoas com } \\
\text { esquizofrenia. }\end{array}$ & $\begin{array}{l}\text { Dificuldades financeiras } \\
\text { foram relacionadas ao } \\
\text { aumento da sobrecarga. } \\
\text { Apoio social, apoio de } \\
\text { outros familiares e a } \\
\text { espiritualidade podem } \\
\text { contribuir para o } \\
\text { enfrentamento da doença. }\end{array}$ & $\begin{array}{c}\text { Os cuidadores estão } \\
\text { constantemente } \\
\text { sobrecarregados e a } \\
\text { carência de recursos } \\
\text { financeiros e sociais } \\
\text { pode contribuir para o } \\
\text { aumento da } \\
\text { sobrecarga. }\end{array}$ \\
\hline
\end{tabular}

\section{DISCUSSÃO}

Todos os artigos analisados mostraram que os cuidadores de pacientes com esquizofrenia são expostos diariamente a altos níveis de sobrecarga. Outros estudos também mostram o impacto que a doença traz à família e principalmente ao cuidador $^{(6,23-26)}$. 
De acordo com os resultados os motivos para a ocorrência da sobrecarga dos cuidadores estão associados à sintomatologia da esquizofrenia (comportamentos agressivos, diminuição da produtividade dos pacientes), ausência de apoio social, preocupações com o futuro, alterações na vida social, cuidados diários como encorajar o paciente a tomar a medicação, fase inicial da esquizofrenia, mudanças na rotina, preconceito, fatores sociodemográficos como idade dos cuidadores, gênero, nível de escolaridade e fatores socioeconômicos como renda familiar e desemprego (dificuldades financeiras).

Os estudos mostraram que o cuidador pode apresentar alterações em sua vida social, como afastar-se de suas atividades de lazer, devido ao acúmulo de responsabilidades iniciando um processo de isolamento social. Desse modo, o cuidador passa a dedicar-se quase exclusivamente ao paciente $\mathrm{e}^{(27-28)}$. O sofrimento com o estigma e o preconceito que os pacientes enfrentam está constantemente presente no cotidiano do cuidador. Todo esse preconceito e falta de compreensão por parte da sociedade acaba gerando mais exclusão social, tanto para o paciente, quanto para a família. Assim, os familiares se isolam e relatam esse afastamento como uma forma que encontram de proteger seu familiar de zombarias e maus tratos.

Um estudo que investigou a veiculação da esquizofrenia na mídia concluiu que a maioria das reportagens encontradas banalizava a doença psiquiátrica, associando-a com casos raros e isolados de violência e criminalidade, contribuindo para aumento da exclusão social(29).

A presença dos sintomas positivos e negativos do transtorno e piora do estado geral do paciente, foram apontados como fatores que acarretam aumento da sobrecarga para os cuidadores. Assim, o manejo da sintomatologia da doença e um tratamento adequado promovem benefícios ao paciente, mas também ao cuidador, devido à redução da sobrecarga. Os sintomas negativos da esquizofrenia são relatados como os que causam maior sobrecarga subjetiva, quando comparados a sintomas positivos. Isso pode ser explicado porque, nos estudos analisados, os sintomas negativos foram mais frequentes e estáveis, enquanto os sintomas positivos foram mais esporádicos ${ }^{(23)}$.

Cuidadores com problemas econômicos mostraramse mais sobrecarregados que famílias que não enfrentavam algum tipo de problema financeiro. A baixa produtividade dos pacientes e despesas com tratamento acarreta ônus para a família, que necessita arcar com os gastos do paciente. Além disso, muitos cuidadores deixam o emprego após o adoecimento do familiar para dedicarse a este, o que pode aumentar ainda mais a sobrecarga financeira. A difícil inserção e permanência do paciente no mercado de trabalho também contribuem significativamente para aumento da sobrecarga financeira(25).

As preocupações com o futuro e segurança física do paciente foram identificadas como responsáveis por desencadear elevada sobrecarga subjetiva. Os cuidadores mostraram-se temerosos com o que será de seu ente quando estiverem incapacitados de cuidar ou quando falecerem, pois são, muitas vezes, os únicos dispostos a oferecer cuidados. Também temem que, devido à doença, o paciente se exponha a riscos, como brigas, acidentes, tentativas de suicídio ou que alguém se aproveite de sua condição de saúde(23-24).

Diversos estudos mostraram uma correlação entre a baixa escolaridade e níveis elevados de sobrecarga. Acredita-se que, a baixa escolaridade possa trazer aos cuidadores maiores dificuldades em compreenderem a esquizofrenia, o que pode contribuir para o aumento da sobrecarga. Além disso, cuidadores com baixa escolaridade, geralmente, apresentam rendimentos mensais escassos e baixa qualidade de vida, podendo agravar os impactos do transtorno(22).

Cuidadores mais velhos apresentaram maiores níveis de sobrecarga objetiva, o que pode ser explicado pelo fato de que, com o avanço da idade há uma maior deterioração natural da saúde física dos indivíduos e maiores dificuldades nas atividades da vida cotidiana(22,30). Outro fato que pode explicar este dado é que com o passar dos anos, o paciente passa a apresentar maior dependência devido à esquizofrenia ser uma doença crônica. Por outro lado, a sobrecarga subjetiva foi menor nesses cuidadores. É importante considerar que, ao longo dos anos o cuidador e a família conseguem se readaptar e reorganizar diante das adversidades da doença, lidando melhor com o estresse que o transtorno acarreta $^{(30)}$.

A falta de apoio social foi citada em alguns estudos como um importante fator que pode contribuir para o aumento da sobrecarga. Cuidadores que possuíam forte vínculo com outros familiares, participavam de grupos sociais ou mantinham atividades de lazer, apresentaram menores níveis de sobrecarga(21-22). Da mesma forma, cuidadores e pacientes que apresentavam melhor desempenho social também sofriam menos com os impactos da esquizofrenia. 


\section{CONCLUSÃO}

Este estudo buscou identificar as evidências disponíveis na produção científica nacional e internacional sobre os motivos responsáveis pela ocorrência da sobrecarga em cuidadores de pacientes com esquizofrenia, constatando que os cuidados dispensados ao paciente e o convívio diário com o transtorno são responsáveis por desencadear altos níveis de sobrecarga.

A falta de apoio social é um importante fator que pode contribuir para o aumento da sobrecarga, sendo assim, o vínculo entre a equipe de saúde e a família deve ser fortalecido, com vistas ao aumento na qualidade de vida dos portadores de esquizofrenia e seus familiares.

Além disso, esforços devem ser realizados com o intuito de desmistificar a esquizofrenia, pois esta ainda é vista com preconceito por parte da população, inclusive por profissionais da saúde. Assim, o entendimento do transtorno pode melhorar a inserção social dos pacientes e familiares.

Destaca-se a necessidade do manejo da sintomatologia da doença, a fim de melhorar a qualidade de vida dos pacientes e também cuidadores, pois os sintomas da doença podem aumentar o estresse no ambiente familiar, o que contribui para maior sobrecarga.

O cuidador também precisa de cuidados da equipe de saúde e deve ser atendido de acordo com suas necessidades biopsicossociais. Os estudos mostraram que problemas com insônia, gastrite, depressão e ansiedade foram percebidos pelos cuidadores após o adoecimento de seu familiar.

Ressalta-se a importância do incentivo e apoio aos pacientes com o intuito de desenvolverem atividades laborais, sejam em oficinas nos Centro de Apoio Psicossocial (CAPS) ou através de parcerias com outras instituições, independente de remuneração, mas visando a ressocialização dos pacientes e maior autonomia e independência destes.

É evidente que a família é fundamental no processo de reabilitação e socialização dos pacientes, portanto os profissionais de enfermagem devem promover ações de acolhimento, escuta, esclarecimentos acerca da doença, auxílios nos momentos de crise, além de incentivar a participação do cuidador no processo de reabilitação psicossocial.

$\mathrm{O}$ adoecimento e o processo de enfrentamento da doença gera uma série de necessidades no âmbito familiar. Dessa forma, este estudo busca despertar não apenas os profissionais envolvidos na assistência psiquiátrica, mas todos aqueles que, de forma direta ou indireta, venham oferecer assistência a cuidadores ou pacientes com esquizofrenia.

Espera-se que este estudo possa contribuir para ampliar os saberes na assistência psiquiátrica a fim de que surjam novos avanços no cuidado de enfermagem prestado aos pacientes e seus cuidadores.

7. Gomes MS, Mello R. Sobrecarga gerada pelo convívio com o portador de esquizofrenia: a enfermagem construindo o cuidado à família. SMAD, Rev. Eletrônica Saúde Mental Álcool Drog. [Internet]. 2012 [cited 2012 fev 6];8(1):2-8. Available from: www.eerp.usp.br/resmad/artigos/SMAD\%20v8n1\%20a02.pdf 8. Mendes KS, Silveira RCCP, Galvão CM. Revisão integrativa: método de pesquisa para a Incorporação de evidências na saúde e na enfermagem. Texto Contexto Enferm. [Internet]. 2008 [cited 2012 fev 6];17(4):758-64. Available from: http://www.scielo.br/pdf/spp/v17n2/a12v17n2.pdf

9. Gülseren L, Cam B, Karakoç B, Yigit $T$, Danaci $A E$, Çubukcuogluz $Z$, et al. The Perceived Burden of Care and its Correlates in Schizophrenia. Turkish Journal of Psychiatry. [Internet]. 2010 [cited 2012 mar 4]:1-8. Available from: http://www.turkpsikiyatri.com/PDF/C21S3/en/765.pdf 10. Li J, Lambert CE, Lambert VA. Predictors of family caregivers' burden and quality of life when providing care for a family member with schizophrenia in the schizophrenia in the People's Republic of China. Nursing and Health Sciences. [Internet]. 2007 [cited 2012 mar 4];9:192-8. Available from:

http://onlinelibrary.wiley.com/doi/10.1111/j.1442-

2018.2007.00327.x/pdf

11. Gonçalves-Pereira M, Xavier M, Wyngaarden B, Papoila AL, Schene $\mathrm{AH}$, Caldas-de-Almeida JM. Impact of psychosis on Portuguese caregivers: a cross-cultural exploration of burden, distress, positive aspects and clinical-functional correlates. Soc Psychiatry Epidemiol. [Internet] 2012. [cited 2012 mar 4]. Available from: 
http://www.springerlink.com/content/63t5437914517v81/fulltext .pdf

12. Papastavrou E, Charalambous A, Tsangari H, Karayiannis G. The cost of caring: the relative with schizophrenia. Scand J Caring Sci. [Internet]. 2010 [cited 2012 mar 4];24:817-23. Available from:

http://web.ebscohost.com/ehost/pdfviewer/pdfviewer?sid=2b81f 051-c482-437e-8d9e-

b0204ef348d7\%40sessionmgr111\&vid $=2$ \&hid $=128$

13. Oliveira RM, Furegato ARF. Um casal de idosos e sua longa convivência com quatro filhos esquizofrênicos. Rev. Esc. Enferm. USP [Internet]. 2012 [cited mar 5];46(3):618-25. Available from: http://www.scielo.br/pdf/reeusp/v46n3/13.pdf 14. Souza Filho MD, Sousa AO, Parente ACBV, Martins MCC. Avaliação da sobrecarga em familiares cuidadores de pacientes esquizofrênicos adultos. Psicol. estud. [Internet]. 2010 [cited 2012 mar 5];15(3):639-47. Available from:

http://www.scielo.br/pdf/pe/v15n3/v15n3a22.pdf

15. Zanetti ACG, Galera SAF. O impacto da esquizofrenia para a família. Rev. Gau. Enf. [Internet]. 2007 [cited 2012 mar 5];28(3):385-92. Available

from: http://seer.ufrgs.br/index.php/RevistaGauchadeEnfermage $\mathrm{m} /$ article/view/4689/2596

16. Almeida MM, Schal VT, Martins AM, Modena CM. A sobrecarga de cuidadores de pacientes com esquizofrenia. Rev. Psiquiatr. Rio Gd. Sul. [Internet]. 2010 [cited 2012 mar 5];32(3):73-9. Available from:

http://www.scielo.br/pdf/rprs/v32n3/1312.pdf

17. Albuquerque EPT, Cintra AMO, Bandeira M. Sobrecarga de familiares de pacientes psiquiátricos: comparação entre diferentes tipos de cuidadores. J. Bras. Psiquiatr. [Internet]. 2010 [cited 2012 mar 5];59(4):308-16. Available from:

www.scielo.br/pdf/jbpsiq/v59n4/07.pdf

18. Chien WT, Chan SWC, Morissey J. The perceived burden among Chinese family caregivers of people with schizophrenia. Journal of clinical nursing. [Internet] 2007 [cited 2012 mar 6];16:1151-61. Available from:

http://web.ebscohost.com/ehost/pdfviewer/pdfviewer?sid=c4ba4 947-73af-47b9-b559-

d6edde4ce62b\%40sessionmgr112\&vid =2\&hid $=128$

19. Schulhi PAP, Wadman MAP, Sales CA. O cotidiano familiar da pessoa com esquizofrenia: cuidando no domicílio. Rev. Eletr. Enf. [Internet]. 2011 [cited 2012 mar 6];14(2):16-24. Available from:

http://www.fen.ufg.br/fen_revista/v14/n1/pdf/v14n1a02.pdf 20. Igberase OO, Morakinyo O, Lawan AO, James BO, Omoroaregba JO. Burden of care among relatives of patients with schizophrenia in midwestern Nigeria. International Journal of Social Psychiatry. [Internet]. 2010 [cited 2012 mar 6];58(2):131-7. Available from:

http://isp.sagepub.com/content/58/2/131.long

21. Ukpong DI. Demographic factors and clinical correlates of burden and distress in relatives of service users experiencing schizophrenia: a study from south-western Nigeria. Mental Health Nursing. [Internet]. 2006 [cited 2012 mar 6];15:54-9. Available from:

http://web.ebscohost.com/ehost/pdfviewer/pdfviewer?sid=841ca bb9-bf7f-4356-87f6-

0118392d89aa\%40sessionmgr111\&vid =2\&hid $=128$

22. Tan SCH, Yeoh AL, Choo IBK, Huang APH, Ong SH, Ismail LH, et al. Burden and coping strategies experienced by caregivers of persons with schizophrenia in the community. Journal of Clinical Nursing. [Internet]. 2012 [cited 2012 mar 6];21:2410-18.

Available from:

http://www.ncbi.nlm.nih.gov/pubmed/22889442

23. Awad AG, Voruganti NP. The Burden of Schizophrenia on Caregivers. Pharmacoeconomics. [Internet]. 2008 [cited 2012 jun 2];26(2):149-62. Available from:

http://web.ebscohost.com/ehost/pdfviewer/pdfviewer?sid=22abe 833-bbfa-4f97-93b4-

6d3a45bd04bf\%40sessionmgr113\&vid =2\&hid $=128$

24. Barroso SM, Bandeira M, Nascimento E. Sobrecarga de familiares de pacientes psiquiátricos atendidos na rede pública. Rev. Psiq. Clín. [Internet]. 2007 [cited 2012 jun 2];34(6):270-7.
Available from:

http://www.scielo.br/pdf/rpc/v34n6/v34n6a03.pdf

25. Borba LO, Schwartz E, Kantorski LP. A sobrecarga da família que convive com a realidade do transtorno mental. Acta Paul. Enferm. [Internet]. 2008 [cited 2012 jul];21(4):588-94. Available from: http://www.scielo.br/pdf/ape/v21n4/a09v21n4.pdf 26. Galera SAF, Zanetti ACG, Ferreira GCS, Giacon BCC, Cardoso L. Pesquisas com famílias de portadores de transtorno mental.

Rev. Bras. Enferm. [Internet]. 2011 [cited 2012 ago 22];64(4):774-8. Available from:

http://www.scielo.br/pdf/reben/v64n4/a22v64n4.pdf 27. Giacon BCC, Galera SAF. Ajustamento familiar após o surgimento da esquizofrenia. Rev. bras. enferm. [Internet]. 2013 [cited 2013 out];66(3): 321-6. Available from:

http://www.scielo.br/pdf/reben/v66n3/a03v66n3.pdf 28. Oliveira RM, Facina PCBR, Siqueira Junior AC. A realidade do viver com esquizofrenia. Rev. bras. enferm. [Internet]. 2012 [cited 2013 out];65(2): 309-16. Available from: http://www.scielo.br/pdf/reben/v65n2/v65n2a17.pdf 29. Guarniero FB, Bellinghini RH, Gattaz WF. O estigma da esquizofrenia na mídia: um levantamento de notícias publicadas em veículos brasileiros de grande circulação. Rev. Psiq. Clín. [Internet]. 2012 [cited 2012 ago 25];39(3):80-4. Available from: http://www.scielo.br/pdf/reben/v58n2/a08.pdf

30. Lasebikan VO, Ayinde OO. Family Burden in Caregivers of Schizophrenia Patients: Prevalence and Socio-demographic Correlates. Indian J. Psychol. Med. [Internet].2013; 35(1):60-6. Available from:

http://www.ncbi.nlm.nih.gov/pmc/articles/PMC3701362/

Artigo recebido em 10/08/2012.

Aprovado para publicação em 29/06/2013.

Artigo publicado em 31/03/2014. 